\title{
Clinical management of asthma in 1999: the Asthma Insights and Reality in Europe (AIRE) study
}

To the Editor:

We read with interest the article by RABE et al. [1] and the editorial by KIPS and PAUwels [2] in which the current level of asthma control in Europe, which has fallen far short of the goals for long term asthma management, was discussed.

KIPS and PAuwels [2] point out some important factors as to why asthma management is not successful in Western Europe. Obviously, the implementation of guidelines by doctors and patients has not been successful, and we fully agree that we have to focus on their practical implementation.

Asthma management is obviously much more complex than just the prescription of treatment, and it could be described as a triangle of management in which the patient, substance and device are of equal importance. In both the article and the editorial, this type of concept of asthma management is not explored or discussed.

Choice of inhaler may not only affect the treatment outcome, but it could also influence the patient's willingness to start/continue medication in the longterm. An adequate discussion between patient and clinician, with regard to choice of inhaler, should be routine.

Recently, a review by Cochrane et al. [3] emphasized the importance that inhaler choice has, on the outcome of the asthma treatment. These authors stressed that the health care providers should consider patient compliance, inhalation technique and inhaler type when evaluating and prescribing asthma medication. Several studies have shown the difficulties patients are found to experience with the nonbreathactivated pressurized metered-dose inhaler $[4,5]$.
In light of the Asthma Insights and Reality in Europe study, there is an immediate need to change the perspective from a substance-based approach to one in which the patient, the substance and the inhaler are in focus. Today, when there is little difference between inhaled steroids in low dose, the most important factor governing treatment outcome may well be the choice of inhaler.

\section{P. Bergquist*, G.K. Crompton ${ }^{\#}$}

*International Marketing Director, Galena a.s., Czech Republic. ${ }^{\# 14}$ Midmar Drive, Edinburgh EH10 6BU Scotland, UK.

\section{References}

1. Rabe KF, Vermeire PA, Soriano JB, Maier WC. Clinical management of asthma in 1999: the Asthma Insights and Reality in Europe (AIRE) study. Eur Respir J 2000; 16: 802-807.

2. Kips JC, Pauwels RA. Asthma control: where do we fail? Eur Respir J 2000; 16: 797-798.

3. Cochrane MG, Bala MV, Downs KE, Mauskopf J, Ben-Joseph RH. Inhaled corticosteroids for asthma therapy: patient compliance, devices, and inhalation technique. Chest 2000; 117: $542-550$.

4. Crompton GK. Problems patients have using pressurized aerosol inhalers. Eur J Respir Dis 1982; 119: 101 104.

5. Goodman DE, Israel E, Rosenberg M, Johnston $\mathrm{R}$, Weiss ST, Drazen JM. The influence of age, diagnosis, and gender on proper use of metered-dose inhaler. Am J Respir Crit Care Med 1994; 150: 1256 1261. 